' Department of Prosthodontics and Periodontology, Piracicaba Dental School, University of Campinas, Piracicaba, São Paulo, Brazil.
Corresponding author:

Renata Cunha Matheus Rodrigues Garcia

Department of Prosthodontics and Periodontology

Piracicaba Dental School, University of Campinas

Avenida Limeira, n 901

Piracicaba, São Paulo, Brazil -

13414-903

Phone: + 5519 2106-5240/

Fax: + 5519 2106-5211

e-mail: regarcia@fop.unicamp.br

Editor: Dr Altair A. Del Bel Cury

Received: July 8, 2021

Accepted: September 6, 2021

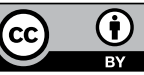

\section{Academic perspectives and psychosocial aspects of final-year dental students during COVID-19 pandemic}

\author{
Mariana Barbosa Câmara-Souza ${ }^{1}$ (D) Fabiana Han Na \\ $\mathrm{Kim}^{1}$ (D), Olívia Maria Costa de Figueredo ${ }^{1}$ (D), Renata \\ Cunha Matheus Rodrigues Garcia' ${ }^{1}$
}

Aim: This cross-sectional observational study aimed to evaluate the influence of the Universities lockdown measures onacademic perspectives and psychosocial aspects of Brazilian finalyear dental students. Methods: 268 undergraduate students regularly enrolled in a Dentistry course at public universities were asked about anxiety, depression, stress sensitivity, and their academic perspectives by using an online survey. The Hospital Anxiety and Depression Scale (HADS) was used to measure anxiety and depression, while the Perceived Stress Scale (PSS) evaluated stress levels. The academic perspective was evaluated by five affirmatives regarding possible difficulties that will be faced when school reopens and after graduation. The possible association between fear of having COVID-19 with psychosocial outcomes and COVID-19 association with academic perspectives were analyzed by ANOVA and chisquare tests, respectively, considering a significance level of $5 \%$. Results: Considering possible associations between the fear of having COVID-19 and psychosocial aspects, significant values were found for anxiety $(P=0.018)$ and stress sensitivity $(P=$ 0.002). Regarding students' academic perspectives, COVID-19 had significant impact on less opportunity to perform procedures $(P=0.023)$, additional expenses with personal protective equipment $(P=0.007)$, and concerns of consulting elderly people $(P=0.012)$. Conclusion: The COVID-19 pandemic led to increased psychological impairments and enlarged concerns with learning and biosecurity, which might impact academic perspectives. Thus, being aware of these apprehensions, university professors and staff can improve the clinical training of final-year dental students in an empathetic way.

Keywords: Anxiety. Depression. Pandemics. Students, dental. 


\section{Introduction}

COVID-19 was first identified in December 2019 in the city of Wuhan, China', and declared a pandemic on March 11, 2020, by the World Health Organization (WHO)2. Among the guidelines established for the control and prevention of COVID-19, social distancing was the most important and widely spread, leading to lockdown in several countries.

The lockdown changed the daily routine, highlighting challenges as working from home and education via internet, as well as led to the loss of social connections by the closure of parks and commercial centers, which modified lifestyle. Thus, the lockdown protocol has provoked the feeling of loneliness, frustration, anger, uncertainty, and powerlessness ${ }^{3,4}$, which may impact the mental health. Researchers investigating the immediate psychological response during the initial stage of the COVID-19 outbreak in China showed that 53.8\% of the respondents had moderate to severe psychological impact ${ }^{5}$, and it could be increased as the pandemic scenario continues.

This perception can be further aggravated when university students are considered. Even before COVID-19, it was estimated that 15 to $25 \%$ of university students have some mental disorder ${ }^{6}$, being those aged from 18 to 20 the most vulnerable to depression and anxiety?. The COVID-19 pandemic led to the suspension of in-person academic activities, and most of them were transferred to online platforms. Remote education has been a temporary strategy to enable classes, exams, and group discussions, maintaining teaching-related activities. Nevertheless, it cannot replace in-person lessons, which are essential for the development of skills and attitudes for integral education ${ }^{8}$. Teaching dentistry encountered significant challenges because it requires hands-on training and patient-care experiences to fully learn dental procedures. Therefore, especially for pre-clinical and clinical students, online education has several limitations ${ }^{9}$, which may lead to higher levels of stress considering the uncertainties ${ }^{10}$.

Thus, dental students are at high risk of developing mental health problems caused by concerns about the redesigned classes, inability to fulfill clinical requirements for graduation and its consequences on their future profession, additional spending on personal protective equipment (PPE), and safety concerns, as the fear of possible cross-contamination between students, patients, and family members ${ }^{11}$. Moreover, considering the negative impact of the pandemic on the economy, it is not known whether patients will be able to continue dental treatments when the university reopens. It is also expected to lower the number of clinical appointments to minimize possible contact among people in the waiting room and to ensure proper disinfection of the office, dental chair, and materials ${ }^{10}$, which will consequently reduce the number of hours of patient-care practice.

The final-year students' concerns may still be associated with the fear of a potential economic recession and lower job offer, besides the occupational risks post-pandemic. The Occupational Safety and Health Administration (OSHA.gov) has classified the dentist's profession at "very high risk" to potential exposure to 
coronavirus through aerosol-generating procedures ${ }^{11,12}$. Thus, it is expected higher costs to implement additional precautions in infection control, which may discourage professionals from starting the career ${ }^{10}$. Therefore, this study aimed to evaluate the influence of the COVID-19 pandemic on academic perspectives and psychosocial aspects of Brazilian final-year dental students.

\section{Material and Methods}

\section{Experimental Design}

This cross-sectional observational study was previously approved by the local Ethics Committee (CAAE: 38129220.7.0000.5418) and included undergraduate students regularly enrolled in the last year of Dentistry course at public universities of São Paulo, Brazil. This survey evaluated the effects of the COVID-19 pandemic on the academic perspectives of dental students, as well as on anxiety, depression, and stress levels. The research was conducted by using an online form, via Google Forms (Google; Mountain View, CA, USA).

\section{Sample and e-Survey}

Students enrolled in the final year of public dental schools in São Paulo were considered for this research. São Paulo is the most populous state in Brazil, with 46.3 million inhabitants, which represents $21.9 \%$ of the Brazilian population. It has seven public dental schools, affiliated with three universities: The University of São Paulo, the University of Campinas, and the São Paulo State University. Thus, the sample size calculation considered the 597 students registered on them. For an 80\% power, design effect of 1.0 and 95\% confidence level, 233 students should participate in this study.

The first page of the online questionnaire presented the Informed Consent Form, which explained the research aims, reported potential risks and highlighted the benefits. Participation was voluntary and not paid; thus, those who accepted the invitation, digitally signed the Informed Consent Form before proceeding to the structured questionnaires. The average time to fill out the entire questionnaire was approximately 15 minutes. Invitation to participate was sent by email and Whatsapp ${ }^{\circledR}$, and the form could be filled out via smartphone, tablet, computer, or any compatible electronic device. Data collection was conducted from September 28 to October 10, 2020.

Initial data collection comprised socioeconomic data, such as sex, monthly income, house sharing, alcohol consumption, smoking habits, and use of medications. Moreover, participants should answer in which dental school was enrolled, and if they already had or were afraid of having COVID-19.

\section{Anxiety, Depression and Stress Levels}

The validated Portuguese version ${ }^{13}$ of the Hospital Anxiety and Depression Scale (HADS) was used to measure anxiety and depression. HADS is a 14-item questionnaire, seven related to anxiety and seven exploring depression. The HADS questions 
address fears, insecurities, joy, slowness, restlessness, among others, and answers are related to the frequency in which the respondent experienced the situations. The score for each item can vary from 0 to 3, with a maximum score of 21 points. Thus, scores from 0 to 7 indicated no anxiety/depression, 8 to 10 mild anxiety/depression, from 11 to 14 moderate anxiety/depression, and scores from 15 to 21 would denote severe anxiety/depression ${ }^{13}$.

The Portuguese version of the Perceived Stress Scale (PSS) ${ }^{14}$ was used to measure stress levels. The PSS was constructed to evaluate how unpredictable and uncontrollable life events were in the last 30 days, from the individual viewpoint. It is a 10-item questionnaire, answered on a Likert scale, ranging from never (0) to always (4) for questions in a negative tone, while for questions with a positive tone this punctuation was inverse ${ }^{14}$. The PSS may be scored from 0 to 40 , and higher values mean higher stress levels.

\section{Academic Perspectives}

The academic perspectives of dental students dealing with the school closure due to the COVID-19 pandemic were evaluated by five affirmatives regarding possible difficulties that will be faced when school reopens and after graduation. The sentences were constructed based on published literature regarding dental education during and post-COVID-19 era ${ }^{9-11}$. Volunteers should indicate whether they agreed, disagreed, or 'do not have an opinion' (neither agree nor disagree), on each of the statements below:

1. "Due to the COVID-19 pandemic, I will have fewer opportunities to perform dental procedures when the clinical practice return";

2. "Due to the COVID-19 pandemic, I will have less chance to learn techniques and I will be less prepared as a dentist";

3. "Due to the COVID-19 pandemic, it will be necessary a higher clinical time to sanitize the environment and change the PPE, which will hinder clinical care";

4. "I am worried about the additional expenses with PPE, mandatory for the clinical care"; and

5. "When the clinics restart, it will be very worrisome to consult elderly patients, considered a risk group for COVID-19".

\section{Statistical Analysis}

The data collected on the digital platform were exported and tabulated. Initially, descriptive statistics were performed to identify frequencies and distributions of the outcomes. Then, analysis of variance was used to test the possible association between fear of having COVID-19 with psychosocial outcomes, while likelihood ratio chi-square was used to verify its association with academic perspectives. The study hypotheses were tested considering a significance level of $5 \%$ and minimum power of $80 \%$. The SAS software version 9.3 (SAS Institute, Inc., Cary, NC, USA) was used for all analyses. 


\section{Results}

Considering the total amount of final-year students from public universities in São Paulo, the response rate was $52.8 \%(n=315)$. However, exclusion due to the use of antidepressants $(n=47)$ yielded a final rate of $44.9 \%(n=268)$. Participants' age varied between 19 and 55 years, mean age of $23.7 \pm 2.8$ years (median $=23$ years). Volunteers' distribution according to each dental school is shown in Table 1.

Table 1. Distribution of volunteers according to the dental school.

\begin{tabular}{lcc}
\hline & Participants (n) & Response Rate (\%) \\
\hline USP - São Paulo School of Dentistry & $58(13 \mathrm{M} ; 45 \mathrm{~F})$ & 43.6 \\
\hline USP - Bauru School of Dentistry & $17(5 \mathrm{M} ; 12 \mathrm{~F})$ & 37.8 \\
\hline USP - School of Dentistry of Ribeirão Preto & $22(5 \mathrm{M} ; 17 \mathrm{~F})$ & 26.5 \\
\hline UNICAMP - Piracicaba Dental School & $51(8 \mathrm{M} ; 43 \mathrm{~F})$ & 69.9 \\
\hline UNESP - School of Dentistry of Araçatuba & $48(10 \mathrm{M} ; 38 \mathrm{~F})$ & 49.0 \\
\hline UNESP - Araraquara School of Dentistry & $32(2 \mathrm{M} ; 30 \mathrm{~F})$ & 41.0 \\
\hline UNESP - School of Dentistry of São José dos Campos & $40(4 \mathrm{M} ; 36 \mathrm{~F})$ & 46.0 \\
\hline
\end{tabular}

USP, University of São Paulo; UNICAMP, University of Campinas; UNESP, State University of São Paulo; M, male; $\mathrm{F}$, female.

Most participants were female (82.5\%), with monthly income between 4 and 10 minimum wages (Brazilian currency), representing the middle and upper-middle class. While during regular academic activities only $29.1 \%$ used to live with parents, during lockdown this amount increased to $85.5 \%$ (see Table 2). From the respondents, only 9 students reported that already had COVID-19, but the fear of having COVID-19 was confirmed by $82.1 \%$.

Table 2. Socioeconomic characteristics of participants.

\begin{tabular}{lcc}
\hline Characteristic & N & $\%$ \\
\hline Gender & 221 & \\
\hline Female & 47 & $82.5 \%$ \\
\hline Male & & $17.5 \%$ \\
\hline Monthly income (Brazilian minimum wage $-\mathrm{R} \$$ ) & 70 & $26.12 \%$ \\
\hline$\leq 4$ & 134 & $50.00 \%$ \\
\hline$>4$ and $\leq 10$ & 58 & $21.64 \%$ \\
\hline$>10$ & 6 & $2.24 \%$ \\
\hline Not reported & & \\
\hline Housing before COVID-19 outbreak & 53 & $19.78 \%$ \\
\hline Alone & 78 & $29.10 \%$ \\
\hline With family & 126 & $47.01 \%$ \\
\hline With friends & 11 & $4.10 \%$ \\
\hline With a partner & & Continue
\end{tabular}


Continuation

\begin{tabular}{lcc}
\hline Housing during lockdown & & \\
\hline Alone & 9 & $3.36 \%$ \\
\hline With family & 229 & $85.45 \%$ \\
\hline With friends & 12 & $4.48 \%$ \\
\hline With a partner & 18 & $6.72 \%$ \\
\hline
\end{tabular}

Considering the psychological outcomes, the frequency of participants classified as having no, mild, moderate, or severe anxiety and depression are presented in Figure 1. As for the academic perspectives after the COVID-19 pandemic, most of the volunteers are in accordance that they will have difficulties when returning clinical activities, as shown in Table 3.

(A)

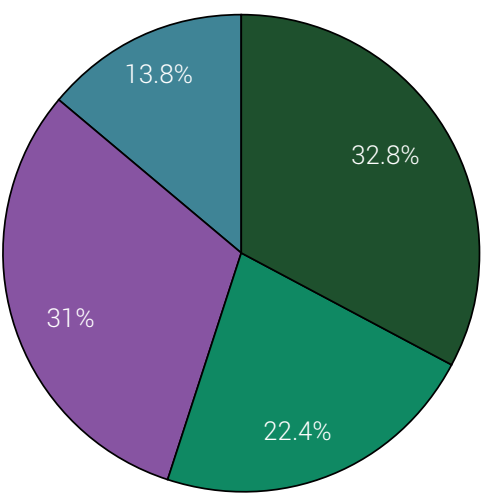

Absent
(B)

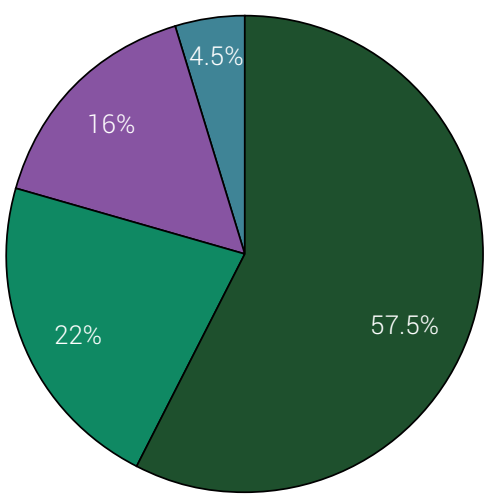

Moderate
Depression

Severe

Figure 1. Distribution of anxiety (A) and depression (B) symptoms among the volunteers.

Table 3. Possible worries associated with clinical care after COVID-19 pandemic, and the percentage of agreement of final-year dental students.

\begin{tabular}{lccc}
\hline Worries about academic perspectives & Agree & Disagree & No opinion \\
\hline $\begin{array}{l}\text { W7- Due to the COVID-19 pandemic, I will have fewer opportunities } \\
\text { to perform dental procedures when the clinical practice return. }\end{array}$ & $89.2 \%$ & $3.7 \%$ & $7.1 \%$ \\
\hline $\begin{array}{l}\text { W2- Due to the COVID-19 pandemic, I will have less chance to learn } \\
\text { techniques and I will be less prepared as a dentist. }\end{array}$ & $72.8 \%$ & $13.1 \%$ & $14.2 \%$ \\
\hline $\begin{array}{l}\text { W3- Due to the COVID-19 pandemic, it will be necessary a higher } \\
\text { clinical time to sanitize the environment and change the PPE, which } \\
\text { will hinder clinical care. }\end{array}$ & $86.2 \%$ & $4.9 \%$ & $9.0 \%$ \\
\hline $\begin{array}{l}\text { W4- I am worried about the additional expenses with PPE, } \\
\text { mandatory for the clinical care }\end{array}$ & $82.1 \%$ & $9.0 \%$ & $9.0 \%$ \\
\hline $\begin{array}{l}\text { W5- When the clinics restart, it will be very worrisome to consult } \\
\text { elderly patients, considered a risk group for COVID-19. }\end{array}$ & $85.4 \%$ & $4.5 \%$ & $10.1 \%$ \\
\hline
\end{tabular}


Possible associations between fear of having COVID-19 and mean values of anxiety, depression, and stress are reported in Table 4. Moreover, it was also associated with the affirmatives representing academic perspectives for school reopening.

Table 4. Mean (standard deviation) or frequencies of the evaluated outcomes considering the fear of having COVID-19.

\begin{tabular}{lccc}
\hline & $\begin{array}{c}\text { Afraid of having } \\
\text { COVID-19 } \\
(\boldsymbol{n}=\mathbf{2 2 0})\end{array}$ & $\begin{array}{c}\text { Not afraid of having } \\
\text { COVID-19 } \\
(\boldsymbol{n}=\mathbf{4 8})\end{array}$ & $P$-value \\
\hline Psychosocial Assessment $^{*}$ & & & \\
\hline Anxiety & $10.00(4.03)$ & $8.35(5.52)$ & 0.018 \\
\hline Depression & $7.01(3.99)$ & $6.35(4.64)$ & 0.318 \\
\hline Stress & $23.87(5.51)$ & $20.90(7.21)$ & 0.002 \\
\hline Academic Perspectives ${ }^{*}$ & & & \\
\hline W1 & $90.91 \%$ & $81.25 \%$ & 0.023 \\
\hline W2 & $75.45 \%$ & $60.42 \%$ & 0.107 \\
\hline W3 & $87.27 \%$ & $81.25 \%$ & 0.457 \\
\hline W4 & $85.45 \%$ & $66.67 \%$ & 0.007 \\
\hline W5 & $88.58 \%$ & $70.83 \%$ & 0.012 \\
\hline W2, & & & \\
\hline
\end{tabular}

W1, W2, W3, W4, W5, affirmatives about academic perspectives that can be found in Table 3.

${ }^{*}$ Data represented by mean (standard deviation);

${ }^{*}$ Data represents the relative frequency of agreement for each affirmative.

\section{Discussion}

This internet-based research assessed final-year dental students from Brazilian public universities in lockdown, regarding academic perspectives and psychosocial outcomes, as well as their association with students' fear of having COVID-19. It was found moderate levels of anxiety and stress, while depression symptoms were absent in more than half of the participants. Furthermore, the great majority of participants agreed that they will have technical difficulties in clinical care and spend significantly more time and money on biosecurity protocols.

Brazil is now considered the epidemic center of the COVID-19 pandemic, due to the steadily increasing caseloads ${ }^{15}$. While several countries had overcome COVID-19 first wave and are now suffering the so-called second wave, Brazil has only experienced a downward trend in hospitalizations between August and November 2020 but has never completely controlled the pandemic. The richest and most populous state of the country, São Paulo, is responsible for approximately $20 \%$ of all cases and deaths, despite the efforts to implement lockdown measures as soon as the WHO declared COVID-19 as a pandemic. Thus, public dental schools have been closed since March 13, 2020, and remained without clinical practice until January 2021. The three universities evaluated are highly developed and the only Brazilian ones included in the Top 50 as World University Ranking. However, the pandemic challenges imposed on dental teaching seem similar to several dental schools around the country and worldwide. 
The sample was mainly represented by female subjects. Although it could be considered a limitation, when evaluating students enrolled in dental schools, the response rates for each sex are similar. It can be supposed that this trend occurs in the entire country, since the number of female dental students are expressively higher than males, with approximately 83,500 females enrolled in $2017^{16}$. As for monthly income, our results are comparable with those obtained in a previous study conducted in Brazilian Northeast ${ }^{17}$, and volunteers could be deemed as middle-to-upper middle class.

Considering the anxiety levels, $53.4 \%$ of volunteers had mild to moderate anxiety, and only $13.8 \%$ showed severe anxiety. These results are in accordance with several published studies, in which participants had mostly mild to moderate anxiety related to the COVID-19 pandemic ${ }^{18-23}$. The anxiety of undergraduate students during the pandemic is especially related to uncertainties about future employments, worries for familiar and own safety, loss of social connections, media speculation and 'culture of fear', prolonged home lockdown, and loss of familiar income ${ }^{18-23}$. All these factors are also possibly related to the moderate stress levels found in the present study. Khan et al. (2020) ${ }^{22}$ found event higher values, reporting that more than $69 \%$ of college students were suffering from mental stress.

Conversely, less than half of the volunteers (42.5\%) had mild to severe depressive symptoms. A previous study, conducted between February and April 2020, found that $35.5 \%$ of participants reported mild to moderate depression ${ }^{24}$. Prolonged self-isolation may modify neurotransmitters' function, reducing serotonin levels. It is relevant to observe that this survey was assessed in October 2020, seven months after school closure, which represented a sample after long periods of lockdown and uncertainties regarding graduation.

Despite $42.5 \%$ of depressive symptoms are a considerably high percentage, another study found that $82.4 \%$ of university students from Bangladesh presented some symptoms of depression ${ }^{25}$. The authors report that Bangladesh students have a history of high levels of depression and anxiety due to the lack of family and social support, and concerns about the professional future. As for the present study, although students were worried about their future, during lockdown they had moved in with their parents, which could be psychological support ${ }^{26}$.

For the affirmative that the COVID-19 pandemic would result in fewer opportunities to perform dental procedures when the clinical practice return, 89.2\% agreed with the statement. Considering a lower possibility of learning techniques and being less prepared for the job market, $72.8 \%$ of the participants demonstrated this concern. Van Doren et al. (2020) ${ }^{9}$ corroborate our findings, stating that the lack of practice and clinical experience will occur due to the limitations of pre-clinical and clinical teaching. It is known that dentistry is a course that requires hands-on training, and despite online teaching is vital in continuing didactic learning during the COVID-19 pandemic, it does not replace in-person clinical experiences.

Regarding biosafety, concerns about longer clinical time for environmental sanitization and PPE replacement were confirmed by $86.2 \%$ of the respondents, while worries due to additional costs with PPE needed for clinical care were expressed by $82.1 \%$ of the 
participants. To the best of our knowledge, no previous studies have addressed those issues. Due to the COVID-19 pandemic, students and professionals have to redouble infection control practices, demanding more protective materials to be used (face shield, N95 mask, cloak), and, consequently, increasing expenses with these materials that have already gone through an astonish inflation. These extra expenses may discourage or even hinder some of these students from public universities to continue their studies. Therefore, institutions should empower students in need, aiming to do not compromise their performance, and, thereby, increase students' stress levels.

Finally, considering that elderly patients are at increased risk of severe illness from the virus that causes COVID-19, 85.1\% of the students reported being very worried about consulting this population. The literature reports that aerosol production, violation of cross-infection protocols, and inadequate prevention for infection control in dental clinics may increase the possibility of transmitting the disease ${ }^{27-29}$. Dental students have reported being afraid not only of becoming infected but also of contaminating people around them. Procedures, such as endodontics and surgery, are the ones with higher-reported concerns, possibly due to the increased aerosol production ${ }^{28}$.

Although this research has obtained important answers on psychosocial aspects and academic perspectives of university students, some limitations should be considered. Data collection was conducted only in October 2020, during the seventh month of lockdown. Different results could have been obtained if we had evaluated the students in the early stages of pandemic onset, or even by January 2021, ten months after dental school closure. Also, it would be interesting to assess these students when universities reopen to confront the academic perspectives reported here with the reality faced by them. A possible shortcoming of this study was volunteers' selection, which was limited only to public universities of São Paulo. It would be relevant to compare this population with students from all over Brazil, and also consider those from private universities. Therefore, further assessments and comparisons are highly encouraged, since they may assist professors and universities to deal with dental students during and after the pandemic.

In conclusion, considering final-year dental students, the COVID-19 pandemic led to increased anxiety, depression, and stress levels, alongside enlarged concerns with learning and biosecurity, that might impact academic perspectives.

\section{Acknowledgments}

This work was supported by the São Paulo Research Foundation (FAPESP) - Brazil under Grant 2017/23429-3; and by the Coordenação de Aperfeiçoamento de Pessoal de Nível Superior - Brasil (CAPES), Finance Code 001.

\section{Data availability}

Datasets related to this article will be available upon request to the corresponding author.

\section{Conflict of interest}

None. 


\section{References}

1. Zhu N, Zhang D, Wang W, Li X, Yang B, Song J, et al. A novel coronavirus from patients with pneumonia in China, 2019. N Engl J Med. 2020 Fev;382(8):727-33. doi: 10.1056/NEJMoa2001017.

2. Sohrabi C, Alsafi Z, O'Neill N, Khan M, Kerwan A, Al-Jabir A, et al. World Health Organization declares Global Emergency: a review of the 2019 novel coronavirus (COVID-19). Int J Surg. 2020;76:71-6. doi: 10.1016/10.1016/j.ijsu.2020.02.034.

3. Ioannidis JPA. Coronavirus disease 2019: The harms of exaggerated information and non-evidence-based measures. Eur J Clin Invest. 2020 Apr;50(4):e13222. doi: 10.1111/eci.13222.

4. Xiang YT, Yang Y, Li W, Zhang L, Zhang Q, Cheung T, et al. Timely mental health care for the 2019 novel coronavirus outbreak is urgently needed. Lancet Psychiatry. 2020 Mar;7(3):228-9. doi: 10.1016/S2215-0366(20)30046-8.

5. Wang C, Pan R, Wan X, Tan Y, Xu L, Ho CS, et al. Immediate psychological responses and associated factors during the initial stage of the 2019 coronavirus disease (covid-19) epidemic among the general population in China. Int J Environ Res Public Health. 2020 Mar;17(5):1729. doi: 10.3390/ijerph17051729.

6. Cavestro JM, Rocha FL. [Depression prevalence among university students]. J Bras Psiquiatr. 2006 Sep;55(4):264-7. Portuguese. doi: 10.1590/S0047-20852006000400001.

7. Othman N, Ahmad F, El Morr C, Ritvo P. Perceived impact of contextual determinants on depression, anxiety and stress: a survey with university students. Int J Ment Health Syst. 2019 Mar;13:17. doi: 10.1186/s13033-019-0275-x.

8. Caldarelli PG, Gabardo MCL. Health training in the context of the COVID-19 pandemic: challenges and perspectives. REFACS. 2021;9(1):188-9. doi: 10.18554/refacs.v9i0.5281.

9. Van Doren EJ, Lee JE, Breitman LS, Chutinan S, Ohyama H. Students' perceptions on dental education in the wake of the COVID-19 pandemic. J Dent Educ. 2020 Jul;5:10.1002/jdd.12300. doi: $10.1002 /$ jdd. 12300 .

10. Wu DT, Wu KY, Nguyen TT, Tran SD. The impact of COVID-19 on dental education in North America-Where do we go next? Eur J Dent Educ. 2020 Nov;24(4):825-7. doi: 10.1111/eje.12561.

11. Iyer P, Aziz K, Ojcius DM. Impact of COVID-19 on dental education in the United States. J Dent Educ. 2020 Jun;84(6):718-22. doi: 10.1002/jdd.12163.

12. U.S. Department of Labor. Occupational Safety and Health Administration. Guidance on preparing workplaces for COVID-19. OSHA 3990-03-2020. 2020. 35p. Available from: https://www.osha.gov/Publications/OSHA3990.pdf.

13. Botega NJ, Bio MR, Zomignani MA, Garcia C Jr, Pereira WA. [Mood disorders among inpatients in ambulatory and validation of the anxiety and depression scale HAD]. Rev Saude Publica. 1995 Oct;29(5):355-63. Portuguese. doi: 10.1590/s0034-89101995000500004.

14. Reis RS, Hino AA, Añez CR. Perceived stress scale: reliability and validity study in Brazil. J Health Psychol. 2010 Jan;15(1):107-14. doi: 10.1177/1359105309346343.

15. Moraes RR, Correa MB, Queiroz AB, Daneris Â, Lopes JP, Pereira-Cenci T, et al. COVID-19 challenges to dentistry in the new pandemic epicenter: Brazil. PLoS One. 2020 Nov; 15(1 1):e0242251. doi:10.1371/journal.pone.0242251.

16. Ministry of Education of Brazil. National Institute of Educational Studies and Research Anísio Teixeira. [Higher education censos: statistical notes]. Brasília: Ministry of Education; 2019 [cited 2021 Jan 3]. Available from: https://download.inep.gov.br/educacao_superior/censo_superior/ documentos/2019/censo_da_educacao_superior_2018-notas_estatisticas.pdf. Portuguese. 
17. Granja GL, Santos JTL, Mariz RC, Araki AT, Souza SV, Nunes JMFF, et al. [Profile of undergraduate students in Dentistry: professional motivations and expectations]. Rev ABENO. 2016 Oct/ Dec;16(4):107-13. Portuguese.

18. Cao W, Fang Z, Hou G, Han M, Xu X, Dong J, et al. The psychological impact of the COVID-19 epidemic on college students in China. Psychiatry Res. 2020 May;287:112934. doi: 10.1016/j.psychres.2020.112934.

19. Wang X, Hegde S, Son C, Keller B, Smith A, Sasangohar F. Investigating mental health of US College Students during the COVID-19 pandemic: cross-sectional survey study. J Med Internet Res. 2020 Sep;22(9):e22817. doi: 10.2196/22817.

20. Debowska A, Horeczy B, Boduszek D, Dolinski D. A repeated cross-sectional survey assessing university students' stress, depression, anxiety, and suicidality in the early stages of the COVID-19 pandemic in Poland. Psychol Med. 2020 Oct;2:1-4. doi: 10.1017/S003329172000392X.

21. Al-Rabiaah A, Temsah MH, Al-Eyadhy AA, Hasan GM, Al-Zamil F, Al-Subaie S, et al. Middle East Respiratory Syndrome-Corona Virus (MERS-CoV) associated stress among medical students at a university teaching hospital in Saudi Arabia. J Infect Public Health. 2020 May;13(5):687-91. doi: 10.1016/j.jiph.2020.01.005.

22. Khan AH, Sultana MS, Hossain S, Hasan MT, Ahmed HU, Sikder MT. The impact of COVID-19 pandemic on mental health \& wellbeing among home-quarantined Bangladeshi students: A cross-sectional pilot study. J Affect Disord. 2020 Dez;277:121-8. doi: 10.1016/j.jad.2020.07.135.

23. Wathelet M, Duhem S, Vaiva G, Baubet T, Habran E, Veerapa E, et al. Factors associated with mental health disorders among university students in france confined during the COVID-19 pandemic. JAMA Netw Open. 2020 Oct;3(10):e2025591. doi: 10.1001/jamanetworkopen.2020.25591.

24. Liu J, Zhu Q, Fan W, Makamure J, Zheng C, Wang J. Online mental health survey in a Medical College in China during the COVID-19 outbreak. Front Psychiatry. 2020 May; 1 1:459. doi: 10.3389/fpsyt.2020.00459.

25. Islam MA, Barna SD, Raihan H, Khan MNA, Hossain MT. Depression and anxiety among university students during the COVID-19 pandemic in Bangladesh: a web-based cross-sectional survey. PLoS One. 2020 Aug;15(8):e0238162. doi: 10.1371/journal.pone.0238162.

26. Mamun MA, Hossain MS, Griffiths MD. Mental health problems and associated predictors among Bangladeshi students. Int J Ment Health Addiction. 2019:1-15. doi: 10.1007/s11469-019-00144-8.

27. Loch C, Kuan IBJ, Elsalem L, Schwass D, Brunton PA, Jum'ah A. COVID-19 and dental clinical practice: students and clinical staff perceptions of health risks and educational impact. J Dent Educ. 2021 Jan;85(1):44-52. doi: 10.1002/jdd.12402.

28. Ataş O, Talo Yildirim T. Evaluation of knowledge, attitudes, and clinical education of dental students about COVID-19 pandemic. PeerJ. 2020 Jul;8:e9575. doi: 10.7717/peerj.9575.

29. Agius AM, Gatt G, Vento Zahra E, Busuttil A, Gainza-Cirauqui ML, Cortes ARG, et al. Self-reported dental student stressors and experiences during the COVID-19 pandemic. J Dent Educ. 2021 Feb;85(2):208-15. doi:10.1002/jdd.12409. 